\title{
BREXIT: LA SECESIÓN DE LA UNIÓN EUROPEA ENTRE TEORÍA Y REALIDAD
}

\author{
ALBERTO LÓPEZ BASAGUREN \\ Catedrático de Derecho Constitucional \\ Universidad del Pais Vasco ${ }^{1}$
}

Sir Humphrey Appleby (Permanent Secretary, dirigiéndose al Ministro): «Britain has had the same Foreign Policy for at least the last 500 years: to create a disunited Europe! (...) Divide and rule, you see! Why should we change now when it has worked so well! (...) We tried to break it up from the outside, but that wouldn't work. Now that we're inside we can make a complete pig's breakfast of the whole thing (...)»

«The Writing on the Wall», episodio 5, primera temporada, de la serie de TV Yes, Minister (BBC, 1980)

\section{SUMARIO}

I. Introducción. II La retirada de la UE como proceso de secesión y el artículo 50 TUE. III. La retirada de la UE y el proceso político-constitucional interno..

IV. Perspectivas de futuro del Brexit: V. Advertencia final.

\section{INTRODUCCIÓN}

La relación del Reino Unido (RU) con la integración supranacional europea ha estado caracterizada por la reticencia, que se asienta en la profunda división de la sociedad británica acerca de su participación en ese proyecto; una división que atraviesa el interior de los partidos políticos, casi sin excepción ${ }^{2}$.

1 Proyecto de Investigación DER 2013-47774-P, financiado por el Ministerio de Economía y Competitividad (MINECO). Este trabajo es deudor de la estancia en Clare Hall (College) y en el Centre for Public Law de la Facultad de Derecho de la Universidad de Cambridge (RU) entre octubre y diciembre de 2016. Quiero expresar mi agradecimiento al Prof. John BeLL por la ayuda prestada durante la estancia.

2 Vid. Curtice, John (2016): «A Question of Culture or Economics? Public Attitudes to the European Union in Britain», The Political Quarterly, vol. 87, n. ${ }^{\circ}$ 2, pp. 209-218 
El tortuoso proceso de acceso del RU a la UE ha dado lugar a una situación singular, en la que disfruta de un estatuto particular, caracterizado por el reconocimiento de excepciones (opt-outs) en la aplicación de algunas disposiciones de los Tratados en el RU, quedando al margen de determinados ámbitos de integración $^{3}$. El RU goza, en medida no desdeñable, de una integración à la carte - $\mathrm{O}$ cherry picking- ${ }^{4}$.

El reconocimiento de un estatuto particular, sin embargo, no ha apaciguado el rechazo radical de un importante sector de la ciudadanía británica a la pertenencia del RU a la UE, que ha jalonado el camino recorrido desde su adhesión. Tampoco lo ha hecho la indiscutible influencia que el RU ha tenido en las políticas de la UE e, incluso, en algunas de sus opciones estratégicas más determinantes 5 .

El inicio del proceso de integración del RU en las Comunidades Europeas y la actual situación, en la que se negocia su retirada de la UE, tienen importantes paralelismos. En 1974, el Partido Laborista sostenía que la adhesión debería haber sido sometida a referéndum, proponía renegociar las condiciones de la incorporación del RU y, tras la renegociación, someter a referéndum la permanencia del país en la organización supranacional o su retirada ${ }^{6}$. Alcanzado el Gobierno, renegoció algunas cuestiones —entre las que destacaban la reducción de la contribución británica al Presupuesto y la renuncia a la armonización del IVA- y convocó un referéndum en el que propugnó el voto favorable al mantenimiento en las Comunidades. El referéndum se realizó en junio de 1975 — primero en el conjunto del RU en su historia constitucional- (1975), y venció ampliamente la opción favorable a la permanencia.

El proceso que ha llevado a la situación actual, en la que el RU ha manifestado su intención de retirarse de la UE (Brexit) reproduce un esquema similar; pero en esta ocasión protagonizado por el Partido Conservador y con el resultado opuesto. La propuesta del premier David Cameron de someter a referéndum la permanencia del RU en la UE — como forma de afrontar la presión interna de los conservadores euroescépticos y el crecimiento del UKIP, radicalmente opuesto a

3 Las excepciones u opt-outs a la aplicación de determinadas normas de los Tratados, están previstas en distintos Protocolos Adicionales al TUE: sobre el euro (Protocolo $n .^{\circ} 15$ ) — del que también está excluida Dinamarca-, sobre el acervo de Schengen integrado en la UE (Protocolos n. ${ }^{\circ} 19 \mathrm{y} \mathrm{n} .^{\circ} 20$, que se refieren también a Irlanda), sobre el Espacio de Libertad, Seguridad y Justicia (Protocolo n. ${ }^{\circ} 21$, que se refiere también a Irlanda) y sobre la Carta de Derechos Fundamentales de la UE (Protocolo n. ${ }^{\circ}$ 30, que se refiere también a Polonia).

4 Vid., sobre la importancia de este estatuto particular, Craig, Paul (2016): «Brexit: A Drama in Six Acts», European Law Review, 4

5 Es tópica la referencia a la influencia del RU en la ampliación de la UE al centro y este de Europa: vid. Lippert, Barbara; Hughes, Kirsty; Grabbe, Heather Becker, Peter: British and German Interests in EU Enlargement. Conflict and Cooperation, The Royal Institute of International Affairs, London-New York, 2001. Sobre la influencia del RU en el proceso legislativo en la UE, vid. HIx, Simon (2016): «Does the UK Have Influence in the EU Legislative Process?», The Political Quarterly, vol. 87, n. ${ }^{\circ}$ 2, pp. 200-208.

6 El resumen del proceso puede verse en MiLler, Vaughne: The 1974-75 UK Renegotiating of ECC Membership and Referendum, House of Commons, Briefing Paper Number 7253, 13 July 2015 
la participación del RU en la integración europea- formó parte del Manifesto del Partido Conservador en las elecciones de 2015, en las que, inesperadamente, obtuvo la mayoría absoluta, aunque frágil, teniendo en cuenta las peculiaridades de la práctica parlamentaria británica ${ }^{7}$. Esa aparentemente cómoda situación parlamentaria le llevó a acelerar la puesta en práctica del compromiso electoral, convocando el referéndum para el 23 de junio de 2016 - a pesar de que el compromiso electoral dejaba margen hasta el fin de 2017—, lo que obligó a afrontar de forma aparentemente precipitada y con estrecho margen temporal la negociación con el Consejo Europeo para satisfacer las demandas del RU. Logrado el Acuerdo en el Consejo Europeo ${ }^{8}$, David Cameron defendió la opción de la permanencia en la UE'. Pero el Partido Conservador se encontraba profundamente dividido, con destacadas figuras encabezando la campaña a favor del abandono de la UE (Leave) y defendiendo la permanencia (Remain) líderes que hasta entonces habían protagonizado intervenciones duramente descalificadoras de la UE, entre ellos el propio Primer Ministro. Además, el Partido Laborista se movió en una gran indefinición, con importantes sectores manteniendo el tradicional discurso reticente con la UE.

El referéndum arrojó un resultado mayoritariamente favorable a la retirada de la UE: el 51,89\% votó a favor de la retirada de la UE frente al 48,11\% que votó a favor de la permanencia en la UE ${ }^{10}$. El Brexit había triunfado. La Ley de convocatoria del referéndum ${ }^{11}$ no exigía umbral mínimo de participación ni porcentaje mínimo de votos a favor de la opción vencedora para atribuir validez al

7 Sobre los antecedentes que llevaron al referéndum, vid. CRAIG, P.: «Brexit: A Drama in Six Acts», cit.

8 Ver el Acuerdo Un nuevo régimen para el Reino Unido en la Unión Europea, aprobado por el Consejo Europeo celebrado los días 18 y 19 de febrero de 2016 (publicado en el DOUE C 69 I, de 23.02.2016).

9 El Departamento del Tesoro del Gobierno británico publicó un White Paper (HM Treasury Analysis: the inmediate economic impact of leaving the EU, Cm. 9292, mayo de 2016). Vid., asimismo, HousE OF COMmons. Foreign Affairs Committee: Article 50 Negotiations: Implications of a 'no deal', HC 1077, 12 de marzo de 2017 , p. 12 , en el que se afirma que el paquete de reformas logrado por David CAMERON «was widely seen by the UK media as insufficiently robust»; y pone ese proceso de renegociación como «example of how time pressure and different negotiating strategies may produce non-optimal results».

10 Un excelente análisis del referéndum sobre el Brexit en CASTEllá Andreu, Josep M. ${ }^{a}$ (2016): «El Referéndum sobre el Brexit: una historia inacabada», Revista de Derecho Político, n. ${ }^{\circ}$ 97, pp. 297-334. Sobre el referéndum es importante el informe de la Electoral Commission: ElECTORAL Commission, The: The 2016 EU Referendum. Report on the 23 June 2016 referendum on the UK's membership of the European Union, September 2016, así como el análisis de los resultados de Goodwin, Matthew J. \& HeAth, Oliver (2016): «The 2016 Referendum, Brexit and the Left Behind: An Aggregate-level Analysis fo the Result», The Political Quarterly, vol. 87, n. ${ }^{\circ}$ 3, pp. 323-332; House of Commons. Public Administration and Constitutional Affairs CомmiтteE: Lessons learned from the EU referendum, Twelfth Report of Session 2016-17, HC 496, 12 de abril de 2017 Vid., un análisis global de los referenda sobre la UE de QvorTRUP, Matt (2016): «Referendums on Membership and European Integration 1972-2015», The Political Quarterly, vol. 87, n. ${ }^{\circ}$ 1, pp. 61-68, que aventuraba la derrota de los partidarios de la permanencia del RU en la UE.

11 Cfr. European Union Referendum Act 2015 [2015, Chapter 36] Sobre esta ley, así como sobre la difícil inserción de la figura del referéndum en el sistema constitucional británico, vid. Douglas-ScotT, Sionaidh (2016): «Brexit, Article 50 and the Contested British Constitution», The Modern Law Review, vol. 79, n. ${ }^{\circ} 6$, pp. 1020-1022 
resultado. De forma generalizada, se consideró que se trataba de un resultado claro que mostraba la voluntad mayoritaria del electorado británico de que el RU abandonara la UE ${ }^{12}$. David Cameron presentó la dimisión como Primer Ministro, siendo sustituido por Theresa May al frente del Gobierno. Comenzaba el proceso para la retirada del RU de la UE.

\section{LA RETIRADA DE LA UE COMO PROCESO DE SECESIÓN Y EL ARTÍCULO 50 TUE}

\section{Retirada de la UE y procesos de secesión}

La UE es una organización internacional con unas características del todo particulares desde el punto de vista jurídico, que la diferencian radicalmente de las organizaciones internacionales tradicionales. Las razones 'cuantitativas' - la amplitud de las competencias de la UE— que singularizan la integración supranacional europea han ido acompañadas de transformaciones 'cualitativas' que la han singularizado jurídicamente. La integración supranacional europea, en todo caso, es una 'Unión de Estados' (tal y como ha expresado en decisiones trascendentales el Tribunal Constitucional alemán ${ }^{13}$ ) que no es identificable, aun hoy, con la integración producida en el seno de los Estados. Sin embargo, la integración entre los Estados que forman parte de la UE es, en muchos ámbitos — muy significativamente, el económico - tan profunda como la que tradicionalmente caracteriza la integración estatal.

La singularidad de la integración supranacional europea tiene consecuencias jurídicas y políticas a la hora de afrontar la hipótesis de retirada de la UE de uno de los Estados miembros que la integran. Desde el punto de vista jurídico, impide reducirlo a una cuestión de aplicación de las normas de Derecho Internacional sobre retirada de un Tratado por parte de un Estado signatario ${ }^{14}$. Desde el punto de vista político, hace que la retirada de la UE de uno de sus Estados miembros sea una hipótesis asimilable, en medida importante, a la secesión en el interior de un Estado, aunque sin ocultar las diferencias nada desdeñables que derivan de los profundos vínculos nacidos en la integración estatal.

12 Vid. House of Lords. Select Committee on the Constitution: The invoking of article 50, 4th. Report of Session 2016-17, HL Paper 44, 13 de septiembre de 2016, p. 4

13 Es recurrente la referencia a esta idea de la UE como 'Unión de Estados', para diferenciarla de Alemania como Estado regulado por una Constitución democrática, desde las Sentencias Solange I — 1974- y Solange II —1986 - luego reiterada en las Sentencias Tratado de Maastricht (1993), Tratado de Lisboa (2009) o, finalmente, la relativa al programa de emisión de bonos - OMT - por parte del BCE (2016).

14 Es la necesaria 'lectura constitucional' del artículo 50 TUE — frente a una lectura 'intergubernamental'- que sostienen Eeckhout, Piet \& Frantziou, Eleni (2016): Brexit and Article 50 TEU: A Constitutionalist Reading, London: UCL European Institute, Working Paper, December 2016, pp. 5 ss. 
En este sentido, hay una diferencia cualitativa sustancial entre un Estado que pretende retirarse de la UE y un territorio de un Estado que pretende la secesión: la condición de Estado, es decir, de miembro reconocido de la comunidad internacional. Esto resulta evidente en un caso como el del RU, uno de los Estados más fuertes, política y económicamente, de la UE, con una importantísima presencia en el ámbito internacional. Si tenemos en cuenta que el TS de Canadá señalaba, ante la hipótesis de una secesión de hecho por parte de un territorio, que su éxito o su fracaso dependería, por una parte, de la efectiva capacidad de controlar el territorio y, por otra, del reconocimiento por parte de la comunidad internacional ${ }^{15}$, es evidente que, en el caso del Brexit, al RU no se le plantearía ninguno de esos dos problemas. Otra cosa es los costes que una retirada en esas condiciones acarree al país que la pone en práctica.

\section{Del silencio al reconocimiento formal del derecho a la retirada}

La posibilidad de retirarse de la UE ha sido una cuestión tradicionalmente polémica en el debate sobre la integración europea. El silencio en los Tratados originarios sobre la posibilidad de que un Estado miembro pudiese retirarse de las Comunidades Europeas, en el contexto de las peculiaridades del Derecho de la UE frente al Derecho internacional, llevó a que se extendiese de forma amplia la teoría de la irreversibilidad de la adhesión ${ }^{16}$; El hecho de que nunca se llegase a plantear, formalmente, la voluntad de retirada de ninguno de los Estados miembros de las Comunidades Europeas evitó tener que poner a prueba la viabilidad de esa interpretación ${ }^{17}$.

La teoría de la irreversibilidad de la adhesión tenía, sin embargo, importantes debilidades desde el punto de vista práctico. Quienes la ponían en entredicho sostenían la dificultad extraordinaria que presentaría rechazar la posibilidad misma de la retirada si un Estado miembro así lo pretendiera ${ }^{18}$. Los autores que sostenían esta visión 'pragmática', en cualquier caso, no consideraban la posibilidad de retirada como un derecho a hacerlo de forma unilateral, sino como una

15 Cfr. Reference re Secession of Quebec, [1998] 2 S.C.R. 217, para. 106

16 Una completa exposición de los argumentos sobre los que se sostiene esta posición en HiLl, J.A. (1982): «The European Economic Community: The Right of Member State Withdrawal», en Georgia Journal of International and Comparative Law, vol. $12, \mathrm{n}^{\circ} 3$, pp. 335 ss.

17 Cfr. Tathaum, A. F. (2012): «Don't mention Divorce at the Wedding, Darling': EU Accession and Withdrawal after Lisbon», en Biondi, A.; Eeckhout, P \& Ripley, S. (eds.): EU Law after Lisbon, Oxford: OUP, p. 143, quien señala que ningún Estado miembro protestó contra la propuesta electoral del Partido Laborista y la efectiva realización del referéndum.

18 Cfr. Berglund, S. (2006): «Prison or Voluntary Cooperation? The Possibility of Withdrawal from the European Union», en Scandinavian Political Studies, vol. 29, n. ${ }^{\circ} 2$, p. 154 En cualquier caso, hay que tener en cuenta que la Convención de Viena sobre Derecho de los Tratados, que se aplica en ausencia de previsión expresa en el Tratado de que se trate, es reticente a la retirada de un Tratado por parte de un Estado signatario: vid. arts. 54 y 56. 
posibilidad abierta, que había que afrontar políticamente por parte de los restantes Estados miembros, que exigiría la negociación entre los miembros de la UE y el Estado que pretendiera retirarse ${ }^{19}$. La demanda de retirada de la UE se asimilaría, básicamente, a un supuesto de secesión que, a pesar de no estar prevista «constitucionalmente», resulta prácticamente imposible de eludir políticamente; pero su viabilidad práctica quedaría al albur de la negociación entre los Estados que permanecen y el que pretende retirarse ${ }^{20}$.

La cuestión, ahora, radica en analizar si las cosas han cambiado con la entrada en vigor del Tratado de Lisboa —en 2009—, que incorporó una cláusula expresa sobre la retirada de la UE de un Estado miembro: el artículo 50 TUE $^{21}$.

El cambio, sin duda, es muy significativo desde el punto de vista formal; nombrar expresamente lo que parecía innombrable tiene una gran trascendencia en la medida en que ya no permite sostener la imposibilidad formal de la retirada y, por tanto, la negativa, amparándose en la legalidad, a tratar una demanda de ese tipo. Un efecto que no es irrelevante. Aunque no parece tan trascendental, sustancialmente, si aceptamos la interpretación de quienes sostenían que, aun en ausencia de previsión expresa en el Tratado, resultaba muy difícilmente eludible la necesidad de afrontarlo ${ }^{22}$.

Más allá del significado de la previsión expresa de la posibilidad de retirada de la UE, interesa analizar los términos en que el artículo 50 TUE regula ese proceso. Este artículo establece, en primer lugar, que cualquier Estado miembro podrá decidir retirarse de la UE y que la adopción de esa decisión se hará de acuerdo a las normas constitucionales del Estado miembro de que se trate (apartado 1). La decisión sobre la voluntad de retirarse queda, estrictamente, en el ámbito del Derecho Constitucional interno, que para la UE se convierte en un requisito de validez: la voluntad de retirarse de la organización supranacional solamente será válida ante la UE —obligándole a cumplir lo previsto en el artículo 50 TUE - cuando sea idóneamente adoptada de acuerdo a las normas constitucionales del Estado que lo pretende ${ }^{23}$. Inmediatamente, el TUE establece que el Estado miembro que haya decidido retirarse notificará «su intención» al

19 Cfr. Berglund, S.: «Prison or Voluntary Cooperation?...», cit., pp. 147 ss.; en la misma línea, Tathaum, A. F.: «'Don't mention Divorce...», cit., pp. 142-143

20 Unos parámetros que sustancialmente coinciden con los establecidos en lo que se puede denominar el paradigma canadiense: Cfr. Reference re Secession of Quebec, cit. Un análisis de este Dictamen en castellano puede verse en López Basaguren, A. (2013) «Los referendos de secesión de Quebec y la doctrina del Tribunal Supremo de Canadá», en Sáenz Royo, E. y Contreras Casado, M. (eds.): La participación política directa. Referéndum y consultas populares, Comuniter, Zaragoza, 2013, pp. 53-91

21 Sobre el artículo 50 TUE, vid., en general, Tathaum, A. F.: «'Don't mention Divorce...», cit., pp. 128-154; Hillion, Chr. (2015): "Accession and Withdrawal in the EU Law of the European Union", en Chalmers, D. \& Arnull, A. (eds.): The Oxford Handbook of European Union Law, Oxford: OUP, pp.

22 Sobre la resistencia a la incorporación de una cláusula secesionista en el Proyecto de Tratado Constitucional por parte de la Comisión y de representantes de distintos Estados, vid. Berglund, S.: «Prison or Voluntary Cooperation?...», cit., pp. 152-154

23 En este sentido, Eeckhout, P. \& Frantziou, E. (2016): Brexit and Article 50 TEU..., cit., p. 13 
Consejo Europeo, abriéndose un proceso de negociación con objeto de alcanzar un acuerdo «que establecerá la forma de su retirada» (apartado 2).

El acuerdo sobre la forma de retirada parece esencial en la arquitectura del artículo 50. Pero el TUE prevé la posibilidad de que no se alcance ningún acuerdo, estableciendo que, en ese caso, transcurridos dos años desde la notificación de la intención de retirarse de la UE «(l)os Tratados dejarán de aplicarse al Estado de que se trate» (apartado 3$)^{24}$. Formalmente, por tanto, el TUE prevé la posibilidad de una retirada sin acuerdo sobre la misma. Lo que significa la aceptación formal de que los Estados miembros tienen un derecho unilateral a la retirada ${ }^{25}$, solo subordinado a un proceso de negociación de dos años (salvo prórroga aprobada en los términos señalados) con el fin de alcanzar un acuerdo sobre la forma de hacerla efectiva.

En esta aceptación de la posibilidad de una retirada unilateral es donde se pone de manifiesto, por una parte, el trascendental significado que, incluso en un proceso de integración supranacional, sigue teniendo la condición de Estado en el seno de la sociedad internacional, frente a la de un territorio interno de un Estado. La condición de miembro de la comunidad internacional del Estado que optase por una retirada unilateral, incluso en contra de las normas 'constitucionales' de la UE, no le abocaría al reto, para poder subsistir, de lograr el reconocimiento de la comunidad internacional como tal Estado. Las mayores o menores dificultades o problemas que ese proceso le acarrease dependerían de la mayor o menor fortaleza — no solo económica- del Estado que se retira de la UE.

\section{PROCESO DE NEGOCIACIÓN PARA LA RETIRADA Y MARCO DE LAS RELACIONES FUTURAS: ¿HACIA LA INVIABILIDAD DEL DERECHO A LA RETIRADA?}

El proceso de negociación para alcanzar el acuerdo de retirada de un Estado miembro parece ser, a todas luces, la clave de bóveda del sistema regulado en el artículo 50 TUE. Esta regulación es relativamente vaga o, si se prefiere, abierta: únicamente establece que el objeto de la negociación será el acuerdo sobre «la forma de su retirada», aunque añade que ese acuerdo se negociará «teniendo en cuenta el marco de sus relaciones futuras con la Unión». Se ha señalado que esa disposición «deja un considerable margen a la interpretación» ${ }^{26}$. También se ha

24 El Consejo Europeo puede decidir ampliar dicho plazo, de acuerdo con el Estado implicado; pero ese acuerdo exige la unanimidad en el Consejo Europeo (apartado 3 del artículo 50 TUE).

25 Cfr. Eeckhout, P. \& Frantziou, E.: Brexit and Article 50 TEU..., cit., p. 25, quienes concluyen que «the decision to withdraw is clearly a unilateral one».

26 Cfr. Hofmeister, H. (2010): “Should I Stay or Should I Go?’ - A Critical Analysis of the Right to Withdraw from the EU», European Law Journal, vol. 16, n. ${ }^{\circ}$ 5, p. 598; en el mismo sentido, HousE OF Commons. Foreign Affairs Committee: Article 50 Negotiations: Implications of a 'no deal', cit., p. 6 
considerado que la disposición utiliza «términos enigmáticos», en la medida en que no precisa qué significa «marco» ni aclara si la 'retirada' y las 'relaciones futuras' tienen que ser objeto de un solo acuerdo o de acuerdos separados ${ }^{27}$. Considero que de la redacción del apartado 2 del artículo 50 TUE se deduce que el objetivo de las negociaciones es el acuerdo sobre la forma y condiciones de la retirada. En la medida en que ese acuerdo debe adoptarse «teniendo en cuenta» el «marco de las relaciones futuras», esta segunda cuestión condiciona el acuerdo sobre la retirada; y ese «marco» puede ser objeto de especificación en el acuerdo sobre la retirada. Pero las «relaciones futuras» entre el Estado miembro que abandona y la UE parecen exigir un acuerdo detallado, más desarrollado que ese «marco», por lo que la estructura de la disposición parece imponer la existencia de acuerdos distintos, aunque directamente interrelacionados ${ }^{28}$.

Es evidente que otras opciones son hipotéticamente posibles. Pero tendría que aceptarlo la UE. En cualquier caso, más allá del interés de la UE en rechazar una pretensión semejante, hay un problema de plazo temporal. A la vista de la experiencia de los procesos de negociación por parte de la UE, resulta prácticamente imposible la conclusión de un acuerdo sobre las relaciones futuras con el Estado que abandona en el plazo establecido en el apartado 2 del artículo 50 TUE ${ }^{29}$; y no parece posible dilatar mucho más la efectividad de la retirada de un país que ya ha manifestado su decisión de abandonar la UE, por la situación de incertidumbre que provoca.

La relativa indeterminación de la regulación contenida en el apartado 2 del artículo 50 TUE, en el contexto de la regulación sobre el proceso de negociación, muestra un desequilibrio en el proceso. La limitación del plazo de negociación a un máximo de dos años, el hecho de que la prórroga de este plazo exija unanimidad en el Consejo Europeo, así como la posibilidad de que si no se alcanza el acuerdo - y no hay prórroga en las negociaciones - se produzca la retirada del Estado miembro («dejarán de aplicarse los Tratados»), muestra la posición

27 Cfr. Eeckhout, P. \& Frantziou, E.: Brexit and Article 50 TEU..., cit., p. p. 24 En la medida en que algunos de los acuerdos pueden tener naturaleza mixta.— con la UE y con los Estados miembros_-, exigiría al Gobierno del RU negociar simultáneamente con unos y con otros: vid. House of Commons. ExiTING THE EUROPEAN UNION COMMITTEE (2017): The process for exiting the European Union and the Government's negotiating objectives..., cit., p. 7

28 Vid. House of Commons. Foreign Affairs Committee: Article 50 Negotiations: Implications of a 'no deal', cit., p. 6, se refiere a tres acuerdos «separados, pero interrelacionados»: un acuerdo sobre el 'divorcio', un acuerdo transitorio y un acuerdo sobre las relaciones futuras o a largo plazo. Vid., asimismo, HousE OF Commons. Exiting the European Union Committee: The process for exiting the European Union and the Government's negotiating objectives: Government Response to the Committee's First Report, HC 1101, 17 de marzo de 2017, p. 11, en la que precisan las cuestiones «absolutamente mínimas» (bare minimun) que tendrían que estar claras en el momento de la retirada del RU de la UE.

29 Vid., en este sentido, House of Commons. Exiting the European Union Committee: The Government's Negotiating Objectives: The White Paper, Third Report of Session 2016-17, HC 1125, 4 de abril de 2017, pp. 82 ss., coancluyendo, p. 84: «It is not yet evident, however, that the two-year timetable for achieving this is realistic». En el mismo sentido, CraIG, P.: «Brexit: A Drama in Six Acts», cit., 4 
dominante de la UE en la negociación ${ }^{30}$. Posición dominante en la medida en que queda en sus manos la amenazante posibilidad de una retirada sin acuerdo. El país que ha decidido retirarse tendría que arrostrar ese riesgo; si eludirlo es una necesidad imperiosa, podrá verse obligado a flexibilizar sus pretensiones.

La inmensa mayoría de los observadores consideran que una retirada de la UE puede ser difícilmente gestionable y está llena de riesgos para el país que la pretenda, incluso con acuerdo; pero si se hace sin acuerdo se considera difícilmente manejable. En un contexto de integración económica tan profunda como la alcanzada a partir de 1992 —aunque el RU no esté integrado en la moneda única- parece difícilmente practicable: los efectos sobre la economía del país que lo pretendiera podrían ser de tal magnitud que, en un contexto democrático, la resistencia interna, tanto de los poderes económicos como de los ciudadanos, en general, podría hacerlo impracticable ${ }^{31}$. Parece que esa convicción sobre la inviabilidad de la retirada de la UE, especialmente en caso de ausencia de acuerdo sobre sus condiciones, subyace en la arquitectura del artículo 50 TUE. El Brexit va a ser, también en este aspecto, un test sobre lo acertado o erróneo de esta convicción.

Ciertamente, el RU es uno de los países más potentes de la UE; por tamaño, por magnitud económica y por relevancia política (y militar). Es, por ello, uno de los países que está en mejores condiciones para afrontar el reto de la retirada, incluso sin acuerdo. Sin embargo, la negociación sobre las condiciones de retirada y, vinculado a ella, la negociación sobre la relación futura entre el RU y la UE se han convertido en el centro de la polémica no solo entre el Gobierno del RU y los representantes de la UE, sino en el seno del propio RU, en el que está teniendo lugar una fuerte confrontación política y sobre la que existe una creciente preocupación en el ámbito económico, especialmente a medida que empiezan a aparecer distintos indicadores que muestran el impacto negativo que está provocando el proceso para la retirada.

Ha transcurrido más de un año desde el referéndum sobre el Brexit. Theresa May accedió a la jefatura del Gobierno con un discurso firme sobre el significado de los resultados y sobre las oportunidades que se le abrían al RU en un futuro fuera de la UE. La premier británica se adueñó del resultado del referéndum determinando su significado, incluso en cuestiones que no formaban parte de lo sometido a votación en el referéndum. Su afirmación «Brexit means Brexit» no admitía

30 Según Eeckhout, P. \& Frantziou, E.: Brexit and Article 50 TEU..., cit., p. 15, del análisis de los trabajos preparatorios de lo que, finalmente, es el artículo 50 TUE, se deduce que «the broad discretion allowed in respect of Article 50(1) was intended to be counterbalanced by stricter conditions under Article 50(3) in order to prevent the withdrawing state holding the Union hostage in the negotiations.»

31 Esa era, precisamente, la hipótesis que barajaban quienes sostenían la interpretación 'pragmática' sobre la posibilidad de la retirada incluso cuando los Tratados no contenían una cláusula expresa que habilitara a ello: vid. Berglund, S.: «Prison or Voluntary Cooperation?...», cit., p. 148 Sobre las implicaciones económicas y políticas de la retirada, vid. HofmeISTER, Hannes: «Should I Stay or Should I Go?'...», cit., pp. 600 ss. 
discusión: la voluntad del electorado exigía recuperar el control ${ }^{32}$ sobre la inmigración sobre la propia legislación y liberar al RU del TJUE, aunque ello significase abandonar el mercado interior europeo.

La comparación entre el referéndum sobre la independencia de Escocia y el referéndum sobre el Brexit - y el proceso político que ha rodeado a uno y a otro- es sumamente llamativo. En lo que respecta a esta cuestión es sorprendente que el Gobierno del RU —y quienes apoyan el Brexit — hayan adoptado la actitud que descalificaban en quienes apoyaban la opción independentista en Escocia $^{33}$. Presentan el futuro del RU, tras la salida de la UE, de forma absolutamente idealizada, como la gran oportunidad de un RU abierto al mundo, líder del libre comercio, a quien esperan con los brazos abiertos los países económicamente más importantes para suscribir acuerdos de libre comercio en idénticas condiciones a las que disfruta como miembro de la UE. Y expresan la absoluta convicción de que el RU va a mantener el acceso al mercado interior europeo, pero libre de algunas de sus reglas — entre otras, la libre circulación de personas y la jurisdicción del TJEU-. Frente a quienes consideran que esas perspectivas son fantasiosas y advierten del negro horizonte —especialmente, económico-al que va a tener que enfrentarse el RU responden que esos temores carecen de fundamento, que son puro alarmismo. En la negociación en curso para la retirada, el RU despliega un discurso muy similar al que utilizaba el Gobierno escocés frente al británico, mientras que desde Bruselas recibe mensajes casi idénticos a los que el Gobierno británico dirigía a los impulsores de la independencia de Escocia ${ }^{34}$.

La segunda cuestión que llama poderosamente la atención al comparar la actuación del Gobierno británico al afrontar el reto planteado por la reclamación de independencia de Escocia y el planteado por el Brexit es la abismal diferencia entre los informes preparados en una y otra ocasión. Ante el Brexit el Gobierno que convocó el referéndum carecía de plan para el caso de la victoria de los partidarios de abandonar la UE, como inmediatamente se puso de manifiesto. Producido el cambio de gobierno, transcurrieron nueve meses hasta que el RU notificó, en aplicación del artículo 50 TUE, su intención de retirarse de la UE. Durante todo ese tiempo, el Gobierno puso de manifiesto la falta de un criterio común

32 El lema expresivo de esta idea, acuñado en la campaña del referéndum, ha sido «Take back control». Sobre lo dudoso de la capacidad de recuperar soberanía en caso de retirada del TU de la UE, vid. GEE, Graham \& Young, Alison L. (2016): «Regaining sovereignty? Brexit, the UK Parliament and the Common Law», European Public Law, vol. 22, n. ${ }^{\circ}$ 1, pp. 131-148

33 En aquella ocasión se contrapusieron la acusación de 'alarmismo' (scaremongering) por parte de los favorables a la independencia contra quienes se oponían y la acusación de 'engaño' (misleading) por parte de quienes se oponían a la independencia frente a quienes la respaldaban: vid. López BASAGUREN, A. (2015): «Escocia: referéndum sobre la independencia y propuesta de reforma de la Devolution», en Revista Española de Derecho Constitucional, n ${ }^{\circ} .104$, pp. 135 ss.

34 El negociador principal de la UE, M. BARNIER, calificaba la actitud del RU en las negociaciones de «nostálgica y falta de realismo»: vid. el diario The Guardian, del 31 de agosto de 2017. En la misma fecha, el diario The Independent titulaba así la información sobre las mismas declaraciones: «UK wants 'impossible' Brexit deal and doesn't understand single marker, says EU negotiator». 
entre sus miembros. Y el Gobierno británico, hasta el último momento, no elaboró ningún informe sobre su posición y los fundamentos en los que se asentaban sus pretensiones ${ }^{35}$. Las dificultades a las que tuvo que enfrentarse el Gobierno de Theresa May en el interior del sistema político británico — a pesar de la mayoría (absoluta) parlamentaria de la que gozaba su partido - para poder imponer sus pretensiones le llevaron a disolver el Parlamento y convocar elecciones anticipadas para el mes de junio de $2017^{36}$. Los resultados electorales frustraron todas las expectativas del Partido Conservador, que perdió la mayoría absoluta en la Cámara de los Comunes, quedando su Gobierno en una débil posición en el Parlamento. El liderazgo político de Theresa May salió fuertemente debilitado, considerándose derrotada su particular interpretación de lo que significaba Brexit. Parece difícil que la mayoría parlamentaria defienda el Brexit duro (bard) que preconizaba y parece haber adquirido más solidez la alternativa de un Brexit blando (soft) o suave (smooth).

Tras un año desde el referéndum, el RU seguía en el punto de partida. El Gobierno inició las negociaciones con la UE (en el mes de junio) sin haber precisado su posición negociadora, más allá de seguir repitiendo la convicción de que sus pretensiones serían necesariamente aceptadas. Tras la publicación del White Paper $^{37}$, en febrero, sólo en el verano ha publicado el Gobierno una serie de Position $\mathrm{Papers}^{38}$ sobre las distintas cuestiones objeto de la negociación sobre el acuerdo de retirada.

El Consejo Europeo aprobó sus orientaciones o líneas directrices para la negociación en abril ${ }^{39}$. En ellas establecía una negociación por fases, de forma que primero habría que negociar el acuerdo sobre la retirada y solo después de resolver esta cuestión, el relativo a las relaciones futuras, cuando el RU sea ya un 'país tercero' $^{40}$. El Consejo Europeo asumía que, a la vista de lo establecido en el apartado 2 del Artículo 50 TUE, en el acuerdo sobre la retirada «debería definirse una

35 Por el contrario, las dos Cámaras han elaborado importantes Informes a través de distintas Comisiones.

36 La convocatoria de elecciones anticipadas estuvo también impulsada, sin duda, por la ventaja de casi treinta puntos frente al Partido Laborista que le otorgaban los sondeos.

37 El White Paper titulado The United Kingdom's exit from and new partnership with the European Union, Cm. 9417, de febrero de 2017, es un compendio de las pretensiones — y de las convicciones_ del Gobierno del RU.

38 Los Position Papers se han publicado entre el 26 de junio y el 21 de agosto de 2017. Se trata de siete documentos de escasas 4 a 6 páginas — salvo los relativos a la situación de los ciudadanos y a Irlanda del Norte-, algunos de ellos sobre cuestiones tangenciales - la confidencialidad en relación con documentos e informaciones respectivas_- faltando documentos sobre alguna de las cuestiones planteadas por la UE como cuestión previa - las responsabilidades financieras o divorce bill_-

39 Cfr. Consejo Europeo: Orientaciones consecutivas a la notificación del Reino Unido en virtud del Artículo 50 del TUE, Bruselas, 29 de abril de 2017. Vid., en relación con este acuerdo la Declaración de los Jefes de Estado $y$ de Gobierno de los 27 Estados miembro, reunión informal, Bruselas, 15 de diciembre de 2016.

40 Lo que significaría que la mayoría requerida para su aprobación ya no es la mayoría cualificada del Artículo 50 sino la unanimidad del Consejo y la ratificación por los Parlamentos de los Estados miembros —y, en algún caso, por Parlamentos regionales—. 
idea general del marco de las relaciones futuras entre el Reino Unido y la Unión»; pero la definición de esa 'idea general' se realizaría en una segunda fase de las negociaciones ${ }^{41}$, una vez constatado que se había avanzado suficientemente en la primera fase. Las negociaciones, de momento, parecen encalladas en este punto, en la medida en que la representación del RU insiste en negociar en paralelo la retirada y las relaciones futuras, rechazando dejar la definición del «marco» para una segunda fase, no concreta las obligaciones financieras que considera debe asumir, exigiendo que sea la UE la que concrete cuáles $\operatorname{son}^{42}$, y no aporta elementos suficientemente satisfactorios para los negociadores de la UE sobre ninguno de los otros dos temas de negociación.

En el proceso de negociación se está comprobando la certera caracterización del proceso de negociación que realizó el TS de Canadá en el Dictamen sobre la secesión de Quebec: la negociación sobre la secesión — como sobre la retiradaes de gran complejidad, porque no se limita a negociar los «logistical details of secession» ${ }^{43}$, y presenta enormes riesgos ( «the devil would be in the details» ${ }^{44}$ ), siendo su resultado absolutamente incierto ${ }^{45}$.

La sensación que transmite la actitud negociadora del Gobierno británico, a juicio de la mayoría de los observadores tanto del RU como de la UE, es de caos; un caos que comenzó en el mismo momento de la convocatoria del referéndum y que no ha hecho sino acrecentarse a medida que el tiempo avanzaba.

Lo más significativo, en este sentido, es la posición del Gobierno británico en relación con la hipótesis de que sus pretensiones de mantener el acceso al mercado interior quedando dispensado de la obligación de respetar la libertad de circulación de personas y de la jurisdicción del TJUE, entre otras particularidades. Sostiene que, en caso de no lograr un acuerdo satisfactorio, optará por retirarse de la UE sin acuerdo, porque considera que para el RU esa opción es preferible a un mal acuerdo ${ }^{46}$. Con esta actitud, el Gobierno británico está poniendo a prueba la presunción de que una retirada sin acuerdo es poco menos que inimaginable, por el grave deterioro que provocaría en la economía británica, al situarla al borde del

41 El negociador principal de la UE designado por la Comisión, Michel BARNIER, señaló que la primera fase debía precisar las obligaciones financieras que debía asumir el RU (la denominada divorce bill), la situación de los ciudadanos en uno y otros países y la cuestión de la frontera en Irlanda del Norte.

42 Sobre las obligaciones financieras del RU la Cámara de los Lores publicó un Informe en el que sostenía que el RU no estaba obligado legalmente a asumir ninguna contribución financiera, salvo que se estableciesen en el acuerdo de retirada: cfr. House of LoRds. European UNION COMMiTTEe: Brexit and the EU budget, 15th Report of Session 2016-17, HL Paper 125, 4 de marzo de 2017, p. 38

43 Cfr. Reference re Secession of Quebec, cit., par. 90

44 Cfr. Reference re Secession of Quebec, cit., par. 91, señalando que «...it would be naive to expect that the substantive goal of secession could readily be distinguished from the practical details of secession.»

45 Algo así venía a considerar la Comisión de Relaciones Exteriores de la Cámara de los Comunes: cfr. House of Commons. Foreign Affairs Committee: Article 50 Negotiations: Implications of a 'no deal', cit.

46 Desde su acceso a la jefatura del Gobierno Theresa MAY acuñó una expresión que ella y su Gobierno han venido repitiendo sin descanso: "No deal is better than a bad deal». 
precipicio, cayendo bruscamente en el ámbito de las normas de la WTO (Organización Mundial de Comercio).

Es difícil saber hasta qué punto la actitud del Gobierno británico se corresponde a la realidad o es una simple estrategia para lograr una posición de fuerza en la negociación al poner en el tejado de la UE la posibilidad de una salida desordenada del RU que podría crear disensiones entre los Estados miembros ${ }^{47}$. Se trata, en cualquier caso, de una estrategia que tiene muchos riesgos ${ }^{48}$, en la que el Gobierno británico tiene las espaldas al descubierto en su propio Parlamento, especialmente tras las elecciones parlamentarias y el cambio de actitud del Partido Laborista hacia un Brexit blando ${ }^{49}$.

\section{LA RETIRADA DE LA UE Y EL PROCESO POLÍTICO- CONSTITUCIONAL INTERNO}

\section{El Brexit entre Gobierno y Parlamento: el caso Miller y sus efectos}

El Gobierno británico pretendió desde el primer momento ser el protagonista absoluto de la determinación del significado de los resultados del referéndum, reclamando la completa libertad para determinar el momento de notificación a la UE de la intención de retirarse de la misma, así como los objetivos y la estrategia del RU en la negociación con la UE sobre la retirada y las relaciones futuras. La Primera Ministra, Theresa May, pretendía mantener en secreto sus pretensiones en la negociación — más allá de lo expresado en sus intervenciones públicas- $-\mathrm{y}$, sobre todo, mantener en secreto su estrategia negociadora y los argumentos en los que iba a asentar la defensa de sus pretensiones $^{50}$. Pretendía excluir la intervención del Parlamento. Utilizó para ello el argumento de que el Gobierno disponía del poder de la royal prerogative, es

47 La revista Politico contenía una información el 3 de agosto de 2017 titulada «Brussels fears Britain's 'Brexit chaos' part of cunning plan», en la que ponían en boca de un diplomático de la UE la convicción de que se trataba de una táctica de negociación para ganar tiempo.

48 Sobre esta posición del Gobierno, la Comisión de Asuntos Exteriores de la Cámara baja del Parlamento británico [House of COMmOns. Foreign AfFAIRs COMmitTeE: Article 50 Negotiations: Implications of a 'no deal', cit.,] considera que no hay que descartar que la opción de que no haya acuerdo ocurra realmente. Sobre la posibilidad del no deal, vid., igualmente, House of Commons. Exiting the European Union Cомmiтtee: The Government's Negotiating Objectives: The White Paper, cit., pp. 86-87, que concluye: «Without an economic assessment of 'no deal' having been done and without evidence that steps are being taken to mitigate what would be the damaging effect of such an outcome, the Government's assertion that «no deal is better than a bad deal», is unsubstantiated. Parliament must be in an informed position to decide whether a proposed deal is, in fact, better or worse than 'no deal'».

49 Sobre lo que se ha denominado periodísticamente el 'U-turn' de los laboristas sobre el Brexit, vid. el artículo de K. StARmer, Minsitro en la sombra (laborista) sobre el Brexit, en el dominical The Observer: «No 'constructive ambiguity'. Labour will avoid Brexit cliff edge for UK economy», del 26 de agosto de 2017.

50 Su expresión favorita era que no pretendía hacer una «transmisión en directo» (a running commentary) de las posiciones del RU. 
decir, el poder residual del Monarca que permite al Gobierno realizar determinados actos sin estar autorizado por una ley del Parlamento ${ }^{51}$. La prerrogativa tiene un especial ámbito de despliegue en el terreno de las relaciones internacionales y en la firma y ratificación de los Tratados internacionales, proceso para el que no es necesaria la aprobación del Parlamento, siendo suficiente el depósito del Tratado en el Parlamento, informándole.

En el caso de la retirada del RU de la UE se planteaban, sin embargo, distintas cuestiones que hacía del tema algo realmente complejo. Especialmente, se planteaba el papel de la European Communittees Act 1972 - como ley constitucional (constitutional statute ${ }^{52}$ ) — en la aplicación del derecho de la UE y su supremacía frente al Derecho interno, limitando la soberanía del Parlamento; el significado del acto de activar (trigger) el artículo 50 TUE y el carácter irreversible o no de esa acción y, en consecuencia, sus efectos sobre los derechos de los ciudadanos británicos cuya fuente es el Derecho de la UE.

Se planteó muy pronto un fuerte debate académico. Quienes consideraban que el Gobierno no disponía del poder de prerrogativa para desvincular al RU de la UE entendían que la European Communnitees Act 1972 es el instrumento legal por el que el Derecho de la UE tiene directa aplicación en el sistema jurídico británico, con primacía sobre las normas internas, por lo que esta ley desplazó el poder de la prerrogativa gubernamental; así, retirarse de la UE significaría derogar ese constitutional statute por un acto del Gobierno ${ }^{53}$. Por el contrario, quienes consideraban que el Gobierno disponía del poder de la prerrogativa, entendían que se trataba de una cuestión relativa a la vinculación a un Tratado internacional, por lo que, en la concepción dualista tradicional del sistema británico, la fuente de los derechos de los ciudadanos británicos no estaba en la European Communittees Act 1972, sino en los Tratados, que fueron ratificados en ejercicio del referido poder de la prerrogativa; la ley de 1972 es el instrumento que permite el efecto de las normas comunitarias en el sistema jurídico británico, distinguiendo entre las obligaciones internacionales

51 La caracterización clásica de la royal prerogative está expuesta sintéticamente en CRAIG, Robert (2016): «Casting Aside Clanking Medieval Chains: Prerogative, Statute and Article 50 after the EU Referendum», The Modern Law Review, vol. 79, n. ${ }^{\circ}$ 6, p. 1043. Una extraordinariamente clara exposición del significado actual de la royal prerogative, en el contexto del debate sobre el Brexit, en BeLL, John (2017): «La Cour suprême de Royaume-Uni et le Brexit», Revue française de droit administratif, n. ${ }^{\circ} 2$, p. 222. Una reconstrucción de la prerrogativa y su relación con la legislación (primaria y secundaria), en la Sentencia de la High Court of England and Wales en el caso Miller -R. (Miller E Dos Santos) v. Secretary of State for Exiting the EU, Judgment of 3.11.2016, [2016] EWHC 2768 (Admin.), Case N. ${ }^{\circ}$ CO/3809/2016 \& CO/3281/2016, para. 24 ss. - y en la Sentencia de la Supreme Court en el mismo caso Miller $-R$. (on the application of Miller and another) v. Secretary of State for Exiting the European Union, Judgment of 24.01.2017, [2017] UKSC 5 (On appeals from: [2016] EWHC 2768 (Admin) and [2016] NIQB 85), para. 50 ss.-

52 Definición realizada por el Lord Justice LAws en el asunto Thoburn v. Sunderland City Council [2003] QB 151 DC, para. 62, que ha quedado como una expresión constitucional consolidada.

53 Vid. esta posición en Phillipson, Gavin (2016): «A Dive into Deep Waters: Article 50, the Prerogative and Parliament», The Modern Law Review, vol. 79, n. ${ }^{\circ}$ 6, pp. 1019-1089, así como en BARBER, Nick; Hickman, Tom \& KIng, Jeff (2016): «Pulling the Article 50 'Trigger': Parliament's Indispensable Role», U.K. Constitutional Law Blog, 27.06.2016 (https://ukconstitutionallaw.org/) 
del RU —asumidas en ejercicio del poder de la prerrogativa — y los efectos del derecho de la UE en el interior del sistema legal británico ${ }^{54}$.

En la base de esta polémica jurídica, sin embargo, se encontraba un hecho de gran trascendencia política: el papel que debía jugar el Parlamento en el proceso de retirada del RU de la UE. En un sistema que sigue reclamando el principio de soberanía parlamentaria - a pesar de todas las vicisitudes sufridas por el mismocomo principio fundamental de su Constitución, resultaba enormemente complicado tratar de justificar la negativa a reconocer un papel protagonista al Parlamento ${ }^{55}$.

Esta polémica doctrinal llegó a los tribunales de justicia que tuvieron que resolverla en el caso Miller $\mathcal{E}$ Dos Santos, primero por la High Court de Inglaterra y Gales ${ }^{56} \mathrm{y}$, finalmente, por la Supreme Court del RU ${ }^{57}$. Se trataba de dos personas de ciudadanía británica que consideraban que la pretensión del Gobierno de activar el artículo 50 TUE tendría el efecto de privarle de sus derechos como ciudadana europea (Gina Miller) y que la pretensión de hacerlo utilizando la prerrogativa, sin intervención del Parlamento, le privaba de sus derechos como ciudadano británico en el proceso legislativo (Deir Tozetti Dos Santos) ${ }^{58}$. Tanto uno como otro Tribunal fallaron a favor de los demandantes, estableciendo que la decisión sobre

54 El defensor más relevante de esta posición ha sido ElLiotT, Mark (2016): «On why, as a matter of law, triggering Article 50 does not require Parliament to legislate», en Public Law for Everyone (Blog), 30.06.2016 (https://publiclawforeveryone.com/). Es interesante la polémica sobre esta cuestión entre CRAIG, R.: «Casting Aside Clanking Medieval...», cit., pp. 1045 ss. y Phillipson, G.: «A Dive into Deep Waters...», cit., esp. pp. 1069 ss.

55 Vid. Douglas-Scotт, S. (2016): «Brexit, Article 50...», cit., p. 1026 El mismo defensor de la tesis de la prerrogativa, entendía, sin embargo, que, en el caso del Brexit había muchas razones a favor de la intervención parlamentaria: «Just because, on my analysis, the Prime Minister can trigger Article 50 without reference to Parliament, it does not follow that that would be a wise or sensible thing to do. Triggering Article 50 would be a highly significant step, given that it would open up the possibility of - even though, as discussed above, it certainly would not render inevitable - the wholesale departure of the UK from the EU. In such circumstances, the case for parliamentary involvement is strong.»: cfr. ELLIOTT, M.: «On why, as a matter of law...», cit.

56 Cfr. High Court of Justice of England and Wales. Queen's Bench Division. Divisional Court (2016): R. (Miller E Dos Santos) v. Secretary of State for Exiting the EU, Judgment of 3.11.2016, [2016] EWHC 2768 (Admin.), Case N. ${ }^{\circ}$ CO/3809/2016 \& CO/3281/2016.

57 UK's Supreme COURT (2OI7): $R$. (on the application of Miller and another) v. Secretary of State for Exiting the European Union, Judgment of 24.01.2017, [2017] UKSC 5 (On appeals from: [2016] EWHC 2768 (Admin) and [2016] NIQB 85)

58 Sobre la Sentencia Miller, vid. Bell, J.: «La Cour suprême de Royaume-Uni et le Brexit», cit., especialmente provechosa para quien no conozca en detalle las singularidades del sistema legal —y judicial- británico; KING, Jeff \& BARBer, Nick (2016): «In Defence of Miller», U.K. Constitutional Law Blog, 22.11.2016 (https://ukconstitutionallaw.org/); Young, Alison L. (2017): «R. (on the Application of Miller) v. Secretary of State for Exiting the EU: Thriller or Vanilla?», European Law Review, n. ${ }^{\circ}$ 42, pp. 280-295; Feldman, David (2017): «Pulling a trigger or starting a journey? Brexit in the Supreme Court», Cambridge Law Journal, vol. 76, n. ${ }^{\circ}$ 2, pp. 217-223; Elliot, Mark (2017): «The Supreme Court's Judgment in Miller: in search of Constitutional Principle», Cambridge Law Journal, vol. 76, n. ${ }^{\circ}$ 2, pp. 257-288. En castellano, vid. Brewer-CARÍAS, Allan R. (2017): «El caso Brexit ante los jueces constitucionales del Reino Unido: comentarios a la Sentencia de la Alta Corte de Justicia de 3 de noviembre de 2016, confirmada por el Tribunal Supremo en Sentencia de 24 de enero de 2017», Revista de Administración Pública, n. ${ }^{\circ}$ 202, pp. 133-156, y Bustos Gisbert, Rafael 
la notificación de la intención de retirarse de la UE exigía aprobación por parte del Parlamento.

La Sentencia de la Supreme Court tiene una gran importancia no solo política, en la medida en que frustró la pretensión del Gobierno de eludir al Parlamento, utilizando la prerrogativa, sino que sus argumentos tienen gran trascendencia en la conformación constitucional del $\mathrm{RU}^{59}$. Partiendo del principio fundamental de la Constitución británica de que, salvo que disposición en contrario de la legislación primaria, la royal prerogative no permite a los Ministros modificar el Derecho legal (statute law) ni el common law, sino que debe ser coherente con ellos y con las decisiones de los Tribunales $^{60}$, señala que la norma general es que el Gobierno puede hacer y deshacer tratados sin necesidad de autorización legislativa, sin que ese poder sea revisable por los tribunales. Principio que se fundamenta en el carácter dualista del sistema británico; lo que significa que carecen de efecto en el Derecho interno, salvo que sean incorporados a través de leyes ${ }^{61}$. Ciertamente, afirma la Supreme Court, esto es lo que hace la EC Act 1972; pero esta Ley hace mucho más, en la medida en que «autoriza un proceso dinámico por el que, sin necesidad de posterior legislación primaria (y, en algunos casos, incluso sin legislación interna de ningún tipo), el derecho de la UE no solo se convierte en fuente de derecho del RU, sino que realmente asume primacía sobre todas las fuentes internas de derecho del RU, incluidas las leyes [primarias, statutes]»; en términos constitucionales, el efecto de la ley de 1972 carece de precedentes ${ }^{62}$.

La $S C$ adopta, así, una perspectiva realista, considerando, frente a quienes no tenían en cuenta esta realidad y trataban el asunto como una cuestión más de ratificación de un Tratado internacional, que el ingreso en las Comunidades Europeas no fue la simple ratificación de un tratado internacional ordinario ${ }^{63}$; es lo que atribuye naturaleza constitucional a la EC Act $1972^{64}$.

(2017): «La desnudez de la Constitución británica. Crónica marciana de la Sentencia de la Suprema Corte de Justicia del Reino Unido de 24 de enero de 2017», Revista Española de Derecho Europeo, n. ${ }^{\circ} 68$.

59 Cfr. Bell, J.: «La Cour suprême de Royaume-Uni et le Brexit», cit., p. 220, quien afirma que la Sentencia Miller «est le plus important que la Cour Suprême britannique a rendu depuis son inauguration en 2009 et, probablement, c'est l'arrêt britannique le plus important depuis le 17ème siècle.».

60 UK's SupREME COURT: $R$. (on the application of Miller and another), cit., para. 50

61 UK's Supreme COURT: $R$. (on the application of Miller and another), cit., para. 55 ss.

62 UK's Supreme Court: $R$. (on the application of Miller and another), cit., para. 60

63 La SC afirma, en este sentido: «The EU Treaties as implemented pursuant to the 1972 Act were and are unique in their legislative and constitutional implications. In 1972, for the first time in the history of the United Kingdom, a dynamic, international source of law was grafted onto, and above, the well-established existing sources of domestic law: Parliament and the courts» -UK's Supreme Court (2OI 7): R. (on the application of Miller and another), cit., para. 90- (énfasis añadido).

64 La Sentencia ha recibido críticas en esta dirección. Así, se le ha achacado una contradicción entre la caracterización de la EC Act 1972 y su consideración de que, sin embargo, esa ley no había alterado la norma de reconocimiento del derecho del $\mathrm{RU}$, o el hecho de que, solo con posterioridad a su aprobación, el sistema jurídico británico se percatara — con el caso Factortame en la sala de justicia de la Cámara de los Lores_ de lo que la ley había supuesto, sin que el legislador fuera consciente de ello en el momento de su aprobación: en sentido 
Establecidos estos principios, para la SC resulta evidente que la EC Act 1972 es una fuente de derechos de los ciudadanos británicos ${ }^{65}$. En este sentido, la retirada de la UE representa, a juicio de la $S C$ «un cambio que es diferente no precisamente en grado sino en naturaleza de la abrogación de concretos derechos, obligaciones o normas derivadas del derecho de la UE», constituyendo un cambio constitucional tan significativo como el que se produjo cuando el derecho de la UE se incorporó por primera vez en el derecho interno por la Ley $[A c t]$ de $1972{ }^{* 6}{ }^{6}$. Por estas razones, la $S C$ considera que el Gobierno no puede decidir la notificación de la intención del RU de retirarse de la UE, sino que requiere el consentimiento del Parlamento a través de legislación primaria ${ }^{67}$.

El Gobierno alegaba que la decisión de retirada de la UE ya había sido tomada por el pueblo en el referéndum. Pero la SC sostiene que la aplicación del resultado del referéndum requiere un cambio en la ley del país (the law of the land), que solo puede hacerse en la forma en que permite la Constitución; es decir, a través de ley parlamentaria. La European Union Referendum Act 2015 no contenía ninguna disposición sobre los efectos del referéndum — frente a lo que sí ha ocurrido en otras ocasiones - , por lo que no ha establecido el cambio legislativo requerido; es decir, no ha cambiado la ley en el sentido que permita a los ministros retirar al RU de la UE sin decisión legislativa. Eso no significa que el referéndum carezca de efectos; significa que, salvo y hasta que se actúe en consecuencia por el Parlamento, su fuerza es política - y muy significativa-, pero no jurídica ${ }^{68}$.

La Sentencia de la $S C$ en Miller dio al traste con la pretensión del Gobierno de decidir el momento de la notificación de la intención de retirarse de la UE por su cuenta, sin someter la cuestión a la aprobación del Parlamento. Pero es evidente que, aunque lo que se discutía en los tribunales se refería a la decisión sobre la notificación, esa decisión judicial afectaba a todo el proceso y, en consecuencia, obligaba al Gobierno a contar con el Parlamento en la determinación de los objetivos que iba a perseguir el RU en la negociación con la UE así como la aprobación, en su caso, del acuerdo de retirada y sobre las relaciones futuras.

El primer efecto de la Sentencia Miller fue la presentación por el Gobierno de su White Paper sobre la retirada y la negociación con la UE, a lo que se había

crítico sobre la Sentencia, vid., muy especialmente, Elliot, M.: «The Supreme Court's Judgment in Miller...», cit., pp. 257 ss.; en sentido contrario, vid. Young, A. L.: «R. (on the Application of Miller)...», cit., pp. 290 ss., así como KING, Jeff \& Barber, Nick (2016): «In Defence of Miller», U.K. Constitutional Law Blog, 22.11.2016 (https://ukconstitutionallaw.org/)

65 La EC Act 1972 tiene dos efectos: incorpora derechos y obligaciones de los ciudadanos británicos y establece un nuevo proceso constitucional de producción jurídica en el RU -UK's Supreme CourT: $R$. (on the application of Miller and another), cit., para. 62-. Es decir «the EU Treaties not only concern the international relations of the United Kingdom, they are a source of domestic law, and they are a source of domestic legal rights many of which are inextricably linked with domestic law from other sources.»

66 Cfr. UK's Supreme Court: $R$. (on the application of Miller and another), cit., para. 81 y 86.

67 Cfr. UK's Supreme CourT: $R$. (on the application of Miller and another), cit., para. 86 y 101

68 Cfr. UK's Supreme CourT: $R$. (on the application of Miller and another), cit., para. 121-122 y 124 
negado hasta ese momento ${ }^{69} ; \mathrm{y}$, de forma indirecta, la convocatoria de elecciones anticipadas.

\section{La (Great?) Repeal Bill: ¿una sencilla desconexión de la UE?}

Aunque el debate político y jurídico ha estado centrado durante muchos meses, de forma obsesiva, sobre la decisión de la notificación de la intención de retirarse de la UE y las exigencias jurídicas que la misma debía cumplir, la cuestión más importante, desde el punto de vista jurídico, se centraba en el gran reto de adecuar el sistema legal británico a su desconexión del Derecho de la UE. En este sentido, ha ocupado un lugar especialmente destacado la referencia a lo que, en la retórica grandilocuente utilizada en el discurso político por parte del Gobierno, se dio en denominar la Great Repeal Bill, el Proyecto de Ley de la Gran Derogación. Un título — sin duda pretencioso- con el que se quería expresar la gran trascendencia política del paso que iba a dar el RU con la recuperación del control sobre su sistema jurídico.

La Comisión Constitucional de la Cámara de los Lores publicó un informe sobre la Great Repeal Bill con el que se adelantó a los problemas que iba a presentar la pretensión del Gobierno ${ }^{70}$. Sobre todo, los relativos a la necesidad de ser plenamente conscientes de la complejidad que planteaba al sistema británico la desconexión jurídica de la UE, frente a la simplicidad con que, en ocasiones, parecía que la vislumbraba el Gobierno, el problema que plantearía la pretensión de una ilimitada e incondicionada delegación de poderes al Gobierno para que elaborase la legislación secundaria (delegada) necesaria para la adaptación del derecho de la UE al sistema británico tras los cambios que derivarán de la retirada a partir del momento en que se haga efectiva, y, finalmente, la cuestión de la recuperación de las competencias de la UE y sus consecuencias sobre el sistema de autonomía territorial (Devolution) del RU, de forma que se determinase la atribución a las instituciones autonómicas de los poderes que corresponden a las competencias que sus respectivas leyes (Devolution Acts o Estatutos de autonomía ${ }^{71}$.

El Gobierno publicó, finalmente, su White paper sobre la Great Repeal Bill casi un mes después de hacerse público el informe de la Cámara de los Lores ${ }^{72}$, en el que se ponía de relieve que el contenido del Bill no se correspondía con la

69 Cfr. UK's GOVERnMENT: The United Kingdom's exit from and new partnership..., cit.

70 Vid. House of Lords. Select Committee on the Constitution (2016): The 'Great Repeal Bill' and delegated powers, 9th. Report of Session 2016-17, HL Paper 123, 7 de marzo de 2017. Sobre este Paper, vid. Elliot, Mark \& Tierney, Stephen (2017): «The 'Great Repeal Bill' and Delegated Powers», U.K. Constitutional Law Blog (7.03.2017) (https://ukconstitutionallaw.org/)

71 Sobre lo que supone, desde el punto de vista legislativo, la desconexión de la UE, vid., igualmente, White, Hannah \& RuTTer, Jill (2017): Legislating Brexit. The Great Repeal Bill and the wider legislative challenge, Institute for Government, IFG Analysis, marzo 2017

72 Cfr. UK's Government. Department for Exiting the European Union: Legislating for the United Kingdom's withdrawal from the European Union, Cm. 9446, marzo de 2017 
grandilocuencia empleada en el discurso político gubernamental y reflejada en su título $^{73}$. Sustancialmente, el Gobierno pretendía, a través de la Repeal Bill, derogar la EC Act 1972 manteniendo vigente en el RU, como derecho interno, todo el Derecho de la UE y atribuir al Gobierno amplísimos poderes delgados para hacer las adaptaciones necesarias a ese Derecho y, en su caso, las modificaciones que se considerasen necesarias —incluídas disposiciones de la legislación primaria, statutes $^{74}$ —, en tanto el Parlamento, a través de su actividad legislativa no fuese modificándolo en el sentido que considerase oportuno. Se plantean tres tipos de contenidos en la futura Ley: «derogación» de la EC Act 1972, «conversión» o «incorporación» del Derecho de la UE vigente en el momento de la retirada en Derecho interno del RU y establecimiento de los poderes para dictar legislación secundaria (delegada) para «corregir» las disposiciones del Derecho incorporado en lo que sea necesario para que puedan seguir operando adecuadamente ${ }^{75}$.

Ha sido generalizada la opinión de que el White paper del Gobierno era decepcionante y, al mismo tiempo, preocupante, en la medida en que parecía querer aprovechar el Brexit para alterar profundamente la arquitectura constitucional británica, modificando radicalmente la relación entre Parlamento y Gobierno $^{76}$, evidenciando que el objetivo fundamental del Gobierno no era otro que atribuir al Gobierno un casi ilimitado poder delegado para modificar el Derecho de la UE incorporado como Derecho interno, prácticamente sin control ${ }^{77}$.

Tras las elecciones el Gobierno bajó el tono, comenzando por asignarle un título más aséptico y modesto ${ }^{78}$, presentando ante el Parlamento la European Union (Withdrawal) Bill ${ }^{9}$.

73 Elliot, Mark (2017): «The Government's White Paper on the «Great Repeal Bill»: Some preliminary thoughts», Public Law for Everyone (Blog) (30.03.2017) (https://publiclawforeveryone.com/) califica la denominación del Proyecto de Ley como «spectacularly misleadingly dubbed».

74 Es lo que se conoce como Henry VIII clauses, por las que una Ley primaria — Statute - permite ser modificada o derogada por el Gobierno, con o sin control del Parlamento. Su denominación proviene del Statute of Proclamations 1539, que permitió al Monarca legislar por Decreto.

75 Cfr. UK's Government. Department for Exiting the European Union: Legislating for the United Kingdom's withdrawal from the European Union, cit., p. 12

76 Vid. Barnard, Catherine (2016): «Law and Brexit», Oxford Review of Economic Politicy, vol. 33, n. ${ }^{\circ}$ S1, pp. S9-S10; Elliot, M.: «The Government's White Paper on the «Great Repeal Bill»...», cit., quien considera que el White paper pone de manifiesto que la comprensión por parte del Gobierno de los problemas que supone la desconexión «remains alarmingly sparse, and gives rise to at least as many questions as it answers. (...) the White Paper suggests that the Government's thinking is significantly underdeveloped or otherwise highly problematic.»

77 En este sentido, Elliot, M.: «The Government's White Paper on the «Great Repeal Bill»...», cit., considera que «(i)t is a cause of great regret that the White Paper, far from giving grounds for confidence in relation to these matters, amounts to a source of profound concern»

78 Vid. The Queen's Speech and Associated Background Briefing, on the ocasion of the Opening of Parliament on Wednesday 21 June 2017 (accesible en el sitio web del Gobierno británico: https://www.gov.uk/). Sobre ello, ELliot, Mark (2017): «The 2017 Queen's Speech and the (no longer «Great») Repeal Bill», Public Law for Everyone (Blog) (7.03.2017) (https://publiclawforeveryone.com/)

79 Una sintética exposición del contenido del proyecto de ley puede verse en Simson CaIRD, Jack: «The European Union (Withdrawal) Bill: constitutional change and legal continuity», Second Reading - The 
El Proyecto de Ley ha recibido fuertes críticas porque reincide en los problemas que se habían puesto de relieve ya con antelación sobre dos cuestiones centrales del sistema constitucional británico: el papel del Parlamento y su relación con el Gobierno, por una parte, y los efectos de la recuperación de competencias desde la UE en la distribución territorial del poder entre el Estado británico y las autonomías territoriales (devolved bodies). La Ley sobre la retirada de la UE está llamada a tener una importancia central en el sistema jurídico británico, en la medida en que el montante de legislación que incorpora al RU como legislación interna — la 'legislación conservada de la UE' (retained EU law) — es de una magnitud enorme, por lo que se necesitarán muchos años para 'digerirla'. Está aceptado sin excepción que para realizar esta operación es indispensable que el Parlamento delegue poderes legislativos al Gobierno, para que este lo haga, en gran medida, a través de legislación secundaria (statutory instruments). Pero esa delegación no puede ser ni ilimitada en el tiempo, ni prácticamente libre del estricto control (scrutiny) parlamentario, como pretende el Gobierno.

En cualquier caso, los problemas que plantea el Bill no se limitan a estas grandes cuestiones. Se ha dicho, en este sentido, que el contraste con la «elegante simplicidad de la European Communittees Act 1972... es sorprendente», porque el texto adolece, en unos u otros aspectos, de ambigüedad, imprecisión, prolijidad e innecesaria complejidad, lo que resulta innecesariamente problemático dada la exigencia de certeza y claridad como elementos centrales del principio del imperio de la ley ${ }^{80}$.

La adecuada regulación de la desconexión jurídica del RU respecto a la UE es, sin duda, condición indispensable - junto con el acuerdo sobre la retirada con la UE- para que el Brexit sea ordenado y no caótico, lo que provocaría importantes perjuicios al RU, como han venido anunciando la mayor parte de los observadores. Para lo que es necesario que la ley de desconexión minimice la incertidumbre y la confusión en el ámbito de la legislación vigente y la forma de ir integrándola en el sistema legal británico.

\section{Brexit y sistema de autonomía territorial: la cuestión de Escocia}

En el ámbito constitucional interno el Brexit se enfrenta a otro reto fundamental: la gestión de la retirada teniendo en cuenta la estructura territorial del poder; es decir, las autonomías territoriales ${ }^{81}$. Este reto plantea dos tipos de

\footnotetext{
House of Commons Library Blog (18.07.2017) (https://secondreading.uk/)

80 Cfr. Elliot, Mark (2017): «The Devil in the detail: Twenty questions about the EU (Withdrawal) Bill», Public Law for Everyone (Blog) (14.08.2017) (https://publiclawforeveryone.com/)

81 Sobre el efecto del Brexit sobre la Devolution, vid. Douglas-ScotT, Sionaidh (2016): «Brexit, Article 50...», cit., pp. 1034 ss.; House of Lords. European UnON CommitTeE: Brexit: devolution, 4th. Report of Session 2017-19, HL Paper 9, de 19 de julio de 2017
} 
problemas, directamente interrelacionados, que se influyen recíprocamente, pero que hay que diferenciar. Por una parte, está la cuestión del consenso - políticosobre los términos de la retirada de la UE con los poderes territoriales (devolved bodies). Es una cuestión importante, especialmente en Escocia, en cuyo territorio los resultados del referéndum sobre el Brexit fueron significativamente diferentes a los obtenidos en Inglaterra ${ }^{82}$. Tras el referéndum por la independencia —en septiembre de 2014 - la situación política parece estar cambiando de forma importante en Escocia, a pesar del relativamente corto tiempo transcurrido, entre otras razones, por los efectos del debate en torno a la ampliación de poderes del Parlamento escocés — los trabajos de la Comisión Smith — y la consiguiente aprobación de la Scotland Act 2016. Parecía claro que, tras todo ese proceso se había alcanzado un statu quo en el que parecía muy difícil que se plantease la demanda de un segundo referéndum por la independencia, a pesar de la forma en que jugaba con esa posibilidad algún sector del SNP (Scottish National Party). El riesgo más importante que podía romper esa situación era, precisamente, que hubiese una fractura entre la posición de Escocia y la del conjunto del RU en el referéndum sobre el $B$ rexit ${ }^{83}$, como así ocurrió. Por esa razón, el Gobierno escocés ha exigido un consenso sobre las condiciones de la retirada de la UE entre el Gobierno británico y los de los territorios autónomos ${ }^{84}$. La situación en Escocia respecto al apoyo a la independencia ha cambiado tan significativamente que Nicola Sturgeon, la First Minister escocesa, no reclama un nuevo referéndum sobre la independencia como consecuencia del referéndum sobre el Brexit, sino un acuerdo sobre una retirada de la UE que mantenga al RU dentro del mercado interior europeo; es decir, un Brexit blando. Solo se planteará la demanda de celebración de un segundo referéndum en caso de que esa demanda no sea atendida y se imponga, como pretende el Gobierno británico, un Brexit duro, que deje al RU fuera del mercado interior. El Gobierno británico no ha atendido las demandas del Gobierno escocés.

Esta cuestión tiene, en segundo lugar, una vertiente jurídica, que ha sido tratada por la Supreme Court. En la apelación del caso Miller se acumuló la apelación en el caso McCord's, que había sido resuelto por el Tribunal Superior (High Court) de Irlanda del Norte ${ }^{85}$, por lo que la $S C$ debió abordar, igualmente, las cuestiones

82 En Escocia el $62 \%$ votó a favor de la permanencia, mientras que el $38 \%$ votó a favor de la retirada. En Inglaterra los resultados fueron del $53,4 \%$ favorable a la retirada y $46,6 \%$ favorable a la permanencia. En Gales el $52,5 \%$ a favor de la retirada y el $47,5 \%$ a favor de la permanencia.

83 Cfr. López Basaguren, A.: «Escocia: referéndum sobre la independencia...», cit., p. 165; sobre los posibles efectos tras el referéndum sobre el Brexit, vid. Edward, David and NiC SHuibHNe, Niahm (2016): " "While Europe's eye is Fix'd on Mighty Things": Implications of the Brexit Vote for Scotland», dentro de la sección «Brexit: What next?», European Law Review, n. ${ }^{\circ} 41$, pp. 481-482

84 El Gobierno escocés publicó un White paper sobre esta cuestión en diciembre de 2016: vid. ScOTTish Government: Scotland's place in Europe, Edinburgh, 2016

85 Cfr. High Court of Justice in Northern Ireland: McCord's (Raymons) Application, Queen's Division (Judicial Review) [2016] NIQB 85, Judgment de 28 de octubre de 2016 
relativas a la forma en que la Devolution afectaba a la competencia para decidir sobre la notificación de la intención de retirarse de la UE ${ }^{86}$. Desde el Gobierno de Escocia, preferentemente, se planteaban dos tipos de cuestiones formales. La primera, relativa al hecho de que la Scotland Act imponía un límite al ejercicio de sus competencias en el respeto al Derecho de la UE ${ }^{87}$. Sostenían que, en consecuencia, la retirada de la UE requería la reforma de la Scotland Act y el acuerdo del Parlamento escocés. La segunda cuestión que se planteaba estaba relacionada con la aplicación de la Sewel Convention, que exige el consentimiento de los Parlamentos territoriales para la aprobación por el Parlamento británico de leyes que entran dentro del ámbito de las competencias atribuidas a los devolved bodies en sus respetivas Devolution Acts: una peculiaridad que es consecuencia del principio de soberanía parlamentaria de Westminster.

La $S C$ resolvió negativamente ambas cuestiones, señalando, respecto a la primera, que la existencia de un límite en el respeto al Derecho de la UE en las Devolution Acts solo indica que, en tanto el RU forme parte de la UE ese Derecho es un límite a las competencias de los devolved bodies, de la misma forma que lo es respecto al Parlamento británico; pero no impone una exigencia al RU para permanecer en la UE, por lo que dejará de ser un límite a las competencias territoriales si se produce la retirada ${ }^{88}$.

En lo que respecta a la segunda cuestión, la $S C$ se aferra a una interpretación puramente formalista de las Convenciones constitucionales. A pesar de que la Scotland Act 2016 incorporó la Sewel Convention como disposición legal ${ }^{89}$, sostiene que la convention opera «como un límite político a la actividad del Parlamento del $\mathrm{RU} »^{90}$, sin que los jueces sean sus guardianes, sino «meros observadores», por lo que «pueden reconocer su operatividad», pero «no pueden establecer normas legales sobre su operatividad o finalidad», porque eso es algo que corresponde al mundo político ${ }^{91}$. La $S C$ considera que, con su incorporación a la Scotland Act, el Parlamento británico «no ha pretendido convertir la Sewel Convention en una norma que pueda ser interpretada, y aun menos aplicada, por los tribunales», sino que la reconoce como lo que es: una convención política ${ }^{92}$.

La European Union (Withdrawal) Bill plantea un problema trascendental. La retirada de la UE tendría que suponer que las competencias asumidas por la UE

86 Cfr. UK's Supreme COURT: $R$. (on the application of Miller and another), cit., para. 126 ss.

87 La Section 29(2)(d) de la Scotland Act 1998 establece que cualquier disposición de una ley (Act) del Parlamento escocés queda fuera de su competencia —y, en consecuencia «is not law»— si «is incompatible... with Communitty law».

88 Cfr. UK's Supreme Court: $R$. (on the application of Miller and another), cit., para. 129.

89 La Section 28(8) de la Scotland Act 1998 — de acuerdo con la reforma operada por la Scotland Act 2016 - establece: «(8) But it is recognised that the Parliament of the United Kingdom will not normally legislate with regard to devolved matters without the consent of the Scottish Parliament.»

90 Cfr. UK's Supreme COURT: $R$. (on the application of Miller and another), cit., para. 145

91 Cfr. UK's Supreme Court: $R$. (on the application of Miller and another), cit., para. 146

92 Cfr. UK's Supreme Court: $R$. (on the application of Miller and another), cit., para. 148 y 151 
en el ámbito de competencias que las Devolution Acts atribuyen a los respectivos parlamentos territoriales deberían retornar a éstos. Sin embargo, la section 11 del Bill las atribuye al Gobierno británico (por delegación), dejando en sus manos decidir si — y cuando- pueden ser atribuidas a los devolved bodies ${ }^{93}$. Una cuestión que va a poner a prueba el respeto de la Sewel Convention y el consentimiento del Parlamento escocés a su aprobación.

En cualquier caso, la solución jurídica dada a esta cuestión por la $S C$ deja intacto el problema político. En estos momentos, cuando todo parece indicar que el riesgo de una nueva crisis sobre la independencia de Escocia está lejos del panorama político, la imposición de un Brexit que deje al RU fuera del mercado interior europeo, es el mayor riesgo de tensiones territoriales en el horizonte.

\section{Brexit y proceso de paz en Irlanda del Norte}

Las condiciones de la retirada de la UE por parte del RU y las relaciones futuras entre ambos tiene otro ámbito de especial significado en Irlanda del Norte $^{94}$. Aunque se trata de una cuestión vinculada al sistema de autonomía territorial, tiene connotaciones del todo particulares, aunque, también en este caso, con el riesgo de poner en peligro la actual configuración del RU; es más, hay un sentimiento muy extendido de que el riesgo de que este proceso suponga un cambio radical de situación es mucho mayor en Irlanda del Norte que en Escocia.

También en Irlanda del Norte, una mayoría significativa de los votantes optó por respaldar la permanencia del RU en la UE, con lo que se creaba, al igual que en Escocia, una contradicción con el respaldo mayoritario a la retirada de la $\mathrm{UE}^{95}$.

Desde la perspectiva jurídica, como ya se ha señalado, la cuestión sobre la posible exigencia del consentimiento del Parlamento regional —Northern Ireland Assembly — para la decisión sobre la notificación del artículo 50 TUE fue resuelta por la Supreme Court en los términos que se han explicado. La SC en el caso Miller resuelve la apelación en el caso $M c$ Cords, resuelto en primera instancia por la High Court de Irlanda del Norte ${ }^{96}$, al haberse acumulado los dos asuntos. Pero el

93 Vid. sobre lo que el Gobierno escocés ha definido como 'descarada apropiación de poder' el comentario de Elliot, Mark (2017): «A 'blatant power grab’? The Scottish Government on the EU (Withdrawal) Bill», en el Blog Public Law for Everyone, (10.08.2017) (https://publiclawforeveryone. $\mathrm{com} /$ )

94 Vid. House of Lords. European Union Committee: Brexit: UK-Irish relations, 6th Report of Session 2016-17, HL Paper 76, de 12 de diciembre de 2016

95 En Irlanda del Norte, el 55,8\% votó a favor de la permanencia, mientras el 44,2 votó a favor de la retirada.

96 Cfr. High Court of Justice in Northern Ireland: McCord's, cit., que resuelve, en lo que ahora interesa, en un sentido coincidente con lo que, finalmente, resolvió la Supreme Court en la apelación. 
problema es político; y en Irlanda del Norte la situación tiene unas connotaciones que la hacen especialmente sensible a lo que puede suponer el Brexit si acarrea la reaparición de una frontera rígida o estricta con la República de Irlanda ${ }^{97}$.

El Acuerdo de Belfast (o Acuerdo de Viernes Santo), impulsado y amparado por los Gobiernos del RU y de la República de Irlanda en 1998, que encarriló la violenta confrontación sectaria en la provincia, contempló - entre otras cuestiones ${ }^{98}$ - la posibilidad de un referéndum sobre la unificación de la isla, que fue incorporado a la Section 1 de la Northern Ireland Act 1998. En el apartado 1 de esta section se establece que Irlanda del Norte forma parte del RU, situación «en la que no cesará sin el consentimiento de una mayoría del pueblo de Irlanda del Norte a través del sufragio en una votación (poll)» convocada expresamente a estos efec$\operatorname{tos}^{99}$. En el caso de que la votación se realizara y la mayoría optara por la unificación de la isla, el RU e Irlanda se comprometen a asumir el resultado y, en su caso, a hacerla viable.

La situación en Irlanda del Norte es muy compleja, y la normalización alcanzada es tremendamente frágil ${ }^{100}$. La práctica desaparición de la frontera entre las dos partes de la isla ${ }^{101}$ que siguió al Acuerdo y el fin de la confrontación violenta ha jugado un papel determinante en el apaciguamiento de las tensiones. Preservar esa situación es indispensable para consolidar el proceso y evitar un retroceso ${ }^{102}$.

Para el RU se trata de una cuestión de gran importancia política, fácilmente comprensible si se tiene en cuenta la forma, a veces asfixiante, en que la cuestión irlandesa ha condicionado la política británica desde el último tercio del siglo XIX. El Gobierno británico quiere eludir el retorno a una frontera rígida y mantener la Common Travel Area (CTA) entre Irlanda y el $\mathrm{RU}^{103}$. La UE comparte la

97 Vid. Tonge, Johathan: The Impact and Consequences of Brexit for Northern Ireland, European Parliament, Briefing, Policy Department C: Citizens' Rights and Constitutional Affairs, PE 583116

98 La NI Act 1998 incorpora, igualmente, el North-South Ministerial Council y el British-Irish Council - sec. 52- y la British-Irish Intergovernmental Conference - sec. 54-.

99 Esta cuestión se desarrolla en el Anexo (Schedule) 1 de la NI Act 1998.

$100 \mathrm{La}$ última legislatura duró menos de un año, convocándose elecciones anticipadas en marzo de 2017. Tras ellas, la Assembly está paralizada, al no haber conseguido formar gobierno intercomunitario. Por primera vez, los republicanos lograron la mayoría, por lo que se hace difícil un Gobierno dirigido por los unionistas del DUP; partido que, sin embargo es el soporte del Gobierno de Theresa MaY en Westminster. El DUP está planteando que si no se llega a un acuerdo la alternativa será el gobierno directo desde Londres, lo que el Gobierno parece rechazar.

101 Vid. BIONDI, Filippo (2017): «A mountain to climb; the looming problem of the Northern Irish border», Brexit Blog - LSE Blogs, publicado el 23.06.2017

102 Vid. Morrow, Duncan \& BYrne, Jonny (2017): «Northern Ireland after Brexit: a fragile peace put in jeopardy», Brexit Blog - LSE Blogs, publicado el 11.01.2017

103 Una sintética, clara y precisa explicación del significado de la Common Travel Area (CTA), en McGuinness, Terry and Gower, Melanie (2017): The Common Travel Area, and the special status of Irish nationals in UK law, House of Commons Library, Briefing paper n. ${ }^{\circ} 7661,9$ de junio de 2017. Vid. la exposición que hace sobre esta cuestión el Gobierno británico en su Position paper: UK Government: Northern Ireland and Ireland. Position paper, publicado el 16 de agosto de 2017, pp. 7-10 Esta posición aparecía ya en la Carta de notificación remitida por Theresa MAY al Presidente del Consejo Europeo (accesible en el sitio web del Consejo Europeo). 
preocupación por la situación de Irlanda del Norte y los efectos que el Brexit pueda tener en el proceso de pacificación, por lo que lo incluyó entre los tres temas previos de negociación del acuerdo de retirada, en los que el Consejo Europeo considera indispensable que haya avances significativos para poder pasar a la segunda fase de negociación ${ }^{104}$.

Iniciada ya lo que en el esquema de la UE constituye la primera fase de las negociaciones, el Gobierno británico ha publicado un Position paper, que ha sido rechazado por el negociador de la UE, en la medida en que propone una frontera invisible que no otorga garantías respecto al respeto del sistema legal de la $\mathrm{UE}^{105}$

Las elecciones de 2017 al Parlamento de Westminster han puesto de relieve, una vez más, que la demografía sigue siendo favorable a los unionistas; pero el impacto del Brexit, en la medida en que un porcentaje importante de votantes tradicionales unionistas votaron a favor de permanecer en la UE, podría alterar los equilibrios en relación con la unificación de la isla y la celebración del referéndum que establece la NI Act 1998.

\section{PERSPECTIVAS DE FUTURO DEL BREXIT}

Una de las cuestiones que se ha planteado en el debate sobre el Brexit es la cuestión del carácter reversible o no de la notificación del artículo 50 sobre la intención de retirarse de la UE ${ }^{106}$. El TUE no dice nada explícito sobre esta hipótesis. Sin embargo, se ha sostenido que la afirmación de que, transcurridos dos años desde la notificación, si no hay decisión sobre la prórroga de las negociaciones, los Tratados «dejarán de aplicarse en el Estado miembro de que se trate», debe ser interpretado como una acción irreversible. En el mismo sentido, hay que recordar que una de las cuestiones que era comúnmente aceptada por las partes en el asunto Miller — y que los dos Tribunales sucesivos que lo enjuiciaron consideraron una cuestión no controvertida - era, precisamente, el hecho del carácter irreversible de la notificación.

104 El Consejo Europeo, en sus Directrices, afirmaba su compromiso con la salvaguarda de la paz en Irlanda del Norte y lo consideraba una circunstancia excepcional que requería «soluciones flexibles e imaginativas, incluyendo el objetivo de eludir un hard border, que, sin embargo, reconozca la integridad del ordenamiento jurídico de la Unión»: cfr. European Council: European Council (Art. 50) guidelines for Brexit negotiations, cit., para. 11 En el mismo sentido, desarrollando esas directrices, vid. EUROPEAN COMMISSION: European Commission's draft negotiating directives for Article 50 negotiations with the United Kingdom - QEA, Brussels, 3 May 2017

105 La Comisión sobre la UE de la Cámara de los Lores, en su informe sobre esta cuestión [HousE OF LORDS. EuROPEAN UNION COMMITTEE: Brexit: UK-Irish relations, cit., p. 64, para. 265] señalaba que la principal responsabilidad en ofrecer una solución realista a esta cuestión recae en el Gobierno británico.

106 Vid., sobre esta cuestión, la sintética pero completa exposición del debate en MiLler, Vaughne; LANG, Arabella \& Simson-Caird, Jack: Brexit: Article 50 TEU and the EU Court, House of Commons Library, Briefing paper n. 7763, 14 de noviembre de 2016 
Aunque algunos juristas que defendían las posiciones de los demandantes en el asunto Miller partían, igualmente, de la afirmación de que la notificación era irrevocable ${ }^{107}$, pronto se alzaron prestigiosas voces sosteniendo su reversibilidad: nada hay en el artículo 50 TUE que impida al Estado miembro que ha notificado su intención de retirarse de la UE anular esta notificación durante el periodo de dos años de negociaciones ${ }^{108}$. Si nada dice el TUE en contrario y la retirada es un proceso potencialmente tan gravoso y dañino para la estabilidad y el bienestar económico del Estado miembro que ha decidido retirarse, pero también para los demás países y para la UE como tal, ¿cómo imponer a un Estado miembro que ha cambiado de opinión la inexorabilidad de una retirada que, previsiblemente, nadie desea y a todos perjudica? Es más, si, por una parte, la decisión de retirada es unilateral, la notificación, por otra, manifiesta la «intención» de retirarse y, finalmente, da lugar a un proceso de negociación, no parece descabellado pensar que, dado que el objetivo de la UE es lograr una «unidad cada vez más estrecha» - base de las reticencias a aceptar el derecho a la retirada_-, aceptar la reversibilidad sea lo más lógico, siempre y cuando se realice de buena fe, con objeto de impedir el abuso del artículo 50 TUE ${ }^{109}$.

Ciertamente, se trata de una cuestión plenamente política ${ }^{110}$, lo que creo que no se escapa a ninguno de los juristas que defienden la posibilidad formal de que la notificación pueda ser revocada; pero el Derecho es el marco en el que se despliega legítimamente la política. Carlos Closa sostenía que, más allá de lo que considera «mera sutileza jurídica» (pure legal nicety), era la política la que impedía la revocabilidad de la notificación. Pero la política es cambiante; lo que en el momento de escribir su trabajo parecía indicar que la UE consideraba irreversible — ¿jurídicamente o políticamente? — , en la actualidad parece haber cambiado y desde la UE han empezado a escucharse mensajes en el sentido de que lo mejor que podría hacer el RU es retirar su intención de abandonar la UE. Ni jurídica ni políticamente parece haber para la UE, ahora, un problema sobre la reversibilidad de la notificación por parte del RU..., si el RU cambiara su decisión.

107 Cfr. Barber, N.; Hickman, T. \& King, J.: «Pulling the Article 50 'Trigger'...», cit.

108 Vid. PIRIS, Jean-Claude: «Article 50 is not for ever and the UK could change its mind», en el diario Financial Times del 1 de septiembre de 2016; CrAIG, Paul: «Brexit: Foundational Constitutional and Interpretative Principles, I \& II», Oxford Human Rights Hub, 27 y 28 de octubre de 2016 (y, más recientemente, del mismo autor, un análisis actualizado del debate, en «The Process: Brexit and the anatomy of Article 50», en Fabbrini, Federico (ed.): The Law and Politics of Brexit, Oxford: OUP, 2017, cap. 3); Sarmiento Rodriguez-Escudero, Daniel: «Miller, Brexit and the (maybe not so evil) Court of Justice», Despite our Differences (Blog), el 8 de noviembre de 2016 (https://despiteourdifferencesblog.wordpress.com/) [también publicado en la misma fecha en Verfassungs Blog - On Matters Constitutional (http://verfassungsblog.de/)]; EECKhout, P. \& Frantziou, E.: Brexit and Article 50 TEU..., cit., pp. 37 ss.

109 Cfr. Eeckhout, P. \& Frantziou, E.: Brexit and Article 50 TEU..., cit., pp. 38-39

110 Vid. Closa Montero, Carlos: «Is Article 50 Reversible? On politics beyond legal doctrine», Verfassungs Blog - On Matters Constitutional (http://verfassungsblog.de/) (4 de enero de 2017) quien afirma que «(f)ar from being a pure legal nicety, revocability has huge implications: it determines the framework for political action». 
Eso no significa que las consecuencias políticas de una revocación de la notificación de la intención de retirarse sean irrelevantes. La credibilidad del RU en el seno de la UE quedaría seriamente dañada, por haber puesto a la UE en una situación de tensión inédita y por los daños causados en este proceso. Pero esa es una cuestión distinta.

\section{2. ¿Es reversible la voluntad de retirada expresada en el referéndum sobre el Brexit?}

Se viene debatiendo mucho sobre la posibilidad de que el RU cambie de opinión sobre la retirada de la UE. La percepción es que las actitudes han comenzado a cambiar ${ }^{111}$. Todavía de forma muy limitada — pero de forma creciente-, porque solo ahora acaban de empezar a ser evidentes las dificultades para un acuerdo plenamente satisfactorio para el RU y los indicadores económicos negativos provocados por la decisión de retirarse.

En cualquier caso, la viabilidad política de la reversibilidad de la decisión de retirarse de la UE plantea enormes dificultades prácticas. Es cierto que el referéndum tenía carácter consultivo, por lo que no existe una obligación jurídica de aplicar sus resultados de forma inexorable. En el contexto de un sistema que sigue afirmando la soberanía parlamentaria como su principio básico fundacional, el Parlamento podría revertir la decisión adoptada sobre la notificación de la retirada ${ }^{112}$. Es una posibilidad que, sin embargo, presenta grandes dificultades políticas.

Se puede considerar que unas nuevas elecciones parlamentarias, en las que la mayoría de sus miembros fuese elegido con una clara propuesta de abandono del Brexit, legitimaría a los miembros del Parlamento a votar a favor de la reversión de la decisión de retirarse de la UE. Pero, a pesar de las circunstancias, el conflicto entre la voluntad popular directa y la manifestada a través de la representación no sería fácil de gestionar políticamente. Teniendo en cuenta la amplitud del sentimiento anti-UE en el RU y las características de los líderes Brexiters, con una capacidad de

111 Ha empezado a cambiar la opinión entre comentaristas en los medios de comunicación, especialmente. En lo que se refiere al conjunto de la población, el sondeo de opinión que la prestigiosa empresa YouGov publicó el 15 de junio de 2017 [YouGov-UK (2017): Survey on Brexit, 15 de junio 2017 (accesible en https://yougov.co.uk/)] mostraba que la mayoría de los británicos (70\%) consideraba que había que seguir adelante con la retirada, pero la mayoría $(36 \%)$ consideraba que los resultados electorales abocaban a un peor acuerdo de retirada. Sobre estas bases, el $43 \%$ consideraba que el Gobierno debía mantener sus objetivos de negociación, el $23 \%$ consideraba que debía flexibilizarlos, tratando de lograr un softer Brexit, el 17\% consideraba que había que convocar un segundo referéndum y el $7 \%$ consideraba que el Gobierno, directamente, debía abandonar el objetivo de abandonar la UE. Estos tres últimos grupos suman el 47\%. El sondeo se realizó antes de empezar las negociaciones. Sobre la influencia que pudo tener el Brexit en las elecciones de junio de 2017, vid. Heath, Oliver \& Goodwin, Matthew (2017): «The 2017 General Election, Brexit and the Return of Two-Party Politics: An Aggregate-Level Analysis of the Result», The Political Quarterly, vol. 88, n. ${ }^{\circ} 1$, pp. $1-14$

112 Vid., sobre esta posibilidad, BARnARD, C: «Law and Brexit», cit., p. S8 
radicalizar hasta el extremo la confrontación en el debate político - como demostraron en la campaña del referéndum - y la fortaleza — y agresividad ilimitadade los medios de comunicación favorables a la salida de la UE, esa confrontación sometería al sistema político británico a una situación extrema de tensión.

En este sentido, solo parecería factible un nuevo referéndum sobre la retirada, una vez conocidas las condiciones en las que la misma fuera a materializarse. Desde un punto de vista lógico, parece que el segundo referéndum debería ser necesario en una decisión de estas características. En efecto, la voluntad popular sobre la retirada — como en los referenda sobre la secesión — se manifestó ante una pregunta genérica, que no precisaba las condiciones en que esa retirada fuera a producirse dentro de la diferentes alternativas posibles, y sin saber las condiciones concretas en que la retirada se producirá, lo que no es posible saber hasta la conclusión de las negociaciones entre las partes implicadas ${ }^{113}$. La voluntad manifestada en el referéndum no puede ser un cheque en blanco a las autoridades para que negocien el acuerdo que crean más conveniente o el que sea posible, a la luz de los intereses de la otra parte; ni puede ser una manifestación de voluntad inmodificable, sean cuales sean las condiciones reales en que la retirada vaya a tener lugar, como resultado de las negociaciones. Por la simple razón de que los votantes no pueden quedar vinculados por algo sobre lo que no se les preguntó y sobre lo que no votaron. Ni puede impedirse la rectificación si se considera que la decisión se ha demostrado errónea.

La posibilidad de un segundo referéndum, sin embargo, ha sido rechazada de forma muy mayoritaria, aunque ha empezado a ser defendida crecientemente ante la perspectiva de serio riesgo de colapso ${ }^{114}$. La duda es, por una parte, si las consecuencias — especialmente económicas - de la retirada se habrán manifestado con suficiente claridad antes del momento en que el posible segundo referéndum deba realizarse, por estar a las puertas de la conclusión del periodo de negociaciones; y, por otra, si la creciente conciencia en sectores cualitativamente informados llegará al conjunto de los ciudadanos como para que el segundo referéndum no se convierta en un instrumento que reafirme, ya de forma definitiva, la misma opción. En caso de tomar cuerpo esta posibilidad, tendría que producirse, casi de forma inevitable,

113 En este sentido, Eleftheriadis, Pavlos (2017): «Constitutional Illegitimacy over Brexit», The Political Quarterly, vol. 88, n. ${ }^{\circ}$ 2, pp. 182-188. También, Weale, Albert (2017): «The Democratic Duty to Oppose Brexit», The Political Quarterly, vol. 88, n. ${ }^{\circ}$ 2, pp. 170-181

114 Vid., acerca de esta polémica, BlaIR, Tony (2017): «Brexit and the Centre», accesible en el sitio web del Tony Blair Institute for Global Change (http://institute.global/news/brexit-and-centre); BogDANOR, Vernon (2017): «A second Brexit referendum? It's looking more likely by the day», en el diario The Guardian del 3 de agosto; Bogdanor, Vernon (2017): «Britain and the EU: In or Out - One Year On», Gresham Lecture impartida el 21 de junio de 2017 (https://www.gresham.ac.uk/lectures-and-events/britain-and-the-euin-or-out-one-year-on); ELLIOT, Mark (2016): «Should there, and does there have to, be a second referendum?», en el Blog Public Law for Everyone, (8.07.2016) (https://publiclawforeveryone.com/); FrEEDLAND, Jonathan (2017): «There is still a real chance for a second Brexit referendum», en el diario The Guardian del 14 de julio; Toynbee, Polly (2017): «Can Brexit be stopped? Not by a second referendum», en el diario The Guardian del 17 de julio 
tras unas elecciones en las que se pusiese de relieve un apoyo popular claro a la reversión de la retirada de la UE.

\section{ADVERTENCIA FINAL}

El RU se enfrenta a un reto de una magnitud enorme, de la que su propio Gobierno no parece ser del todo consciente. No solo pone en riesgo, de forma significativa, su nivel de desarrollo económico y bienestar, sino también la estabilidad interna y la propia integridad del país. La cuestión lacerante para el RU es qué obtiene de este proceso. A la vista de la forma en que se van desarrollando los acontecimientos y las circunstancias que lo condicionan, parece que la opción más natural sería la retirada del RU de la UE, manteniéndose dentro del mercado interior europeo en un estatus sustancialmente similar al del EEE -Espacio Económico Europeo o Agreement on the European Economic Area, 1993) que vincula a los países de la EFTA — salvo Suiza con su acuerdo singular- . Se trataría de la opción menos arriesgada y con la que se conciliarían con más facilidad todos los elementos en juego: cumplir, formalmente, el deseo de los Brexiters, eliminando, en gran medida, los efectos económicos de la retirada, así como los riesgos para el mantenimiento de la integridad del RU; aunque sería volver a una situación ya vivida y que, por insatisfactoria, impulsó al RU a adherirse a las Comunidades. Pero nada garantiza que, finalmente, vaya a ser así. Una clarísima manifestación de indicadores negativos que augurasen un negro porvenir — especialmente, económico — al RU podría, quizás, reforzar las opciones de la reversión de la decisión. El error de cálculo de las partes en la negociación podría llevar a una retirada sin acuerdo. Nada debe descartarse completamente. La historia demuestra que los países y los sistemas políticos no siempre saben eludir los riesgos que se les presentan o que ellos mismos se empeñan en provocar.

En cualquier caso, como decía Bertrand Russell ${ }^{115}$, se ha tratado en este trabajo de tomar en consideración algunos hechos que se han considerado relevantes sobre los que hacer algunas conjeturas, pero sin ninguna intención de hacer profecías. En el trabajo académico, sin embargo, no nos podemos limitar, simplemente, a mostrar un ramillete de posibilidades, sino que hay que tratar de aportar elementos que permitan vislumbrar las probabilidades, como, a juicio de Richard Feynman $^{116}$, es exigible en el trabajo científico.

$$
* * *
$$

115 Vid. Russell, Bertrand: Icarus or the Future of Science, 1924. Este opúsculo es una respuesta polémica al texto de John B. S. Haldane: Daedalus or the Future of Science, presentado por el autor en la Heretics society de Cambridge el 4 de febrero de 1923. El texto puede encontrarse ahora en Dronamraju, K. R. (ed.) (1995): Haldane's Daedalus Revisited, Oxford: OUP

116 Cfr. Feynman, Richard: The Meaning of it All: Thoughts of a Citizen-Scientist, Boston: Addison-Wesley, 1998 
TITLE: The withdrawal process from the EU (Brexit).

ABSTRACT: The withdrawal process from the EU (Brexit) raises issues of great significance both in British constitutional law and in EU law, according to Article 50 TEU. Some of the issues raised in the British legal system have been settled by the Supreme Court in the Miller case; but there are others still to be clarified: the role of Parliament in the task of adapting EU law, which the Government is attempting to replace via an unlimited delegation of powers (the Henry VIII clauses); or that of the devolved bodies, which the Government is seeking to exclude from the recovery of powers from the EU. The outcome of the negotiations may jeopardize British internal cohesion, in relation to both Scotland and Northern Ireland. And the circumstances of withdrawal and future relations between the $U K$ and the $E U$ - especially in the case of no deal-could seriously affect the UK's economic wealth and stability. The formal right to withdrawal is thus deeply conditioned by its practical feasibility.

RESUMEN: El proceso de retirada de la UE (Brexit) plantea cuestiones de gran trascendencia en el Derecho Constitucional británico y en el de la UE, a la luz del artículo 50 TUE. Algunos de los problemas planteados en el Derecho británico se han resuelto por la Supreme Court en el asunto Miller; pero otros siguen abiertos: el papel del Parlamento en la adaptación del derecho de la UE, que el Gobierno pretende desplazar a través de la asunción de una ilimitada delegación de poderes (la cláusula Enrique VIII); o el de los territorios autónomos, que pretenden ser marginados de la recuperación de competencias de la UE. El resultado de las negociaciones puede poner en riesgo la cohesión interna británica, tanto con Escocia como con Irlanda del Norte. Y las condiciones de la retirada y de las relaciones futuras entre ambos —especialmente en caso de falta de acuerdo - pueden afectar gravemente a la estabilidad económica del RU. El derecho formal a la retirada queda, así, profundamente condicionado por su viabilidad práctica.

Key Words: Brexit, European Union, International Treaties (withdrawal), Article 50 TEU, UK, Miller case, Royal prerogative, European Communities Act 1972, Scotland, Northern Ireland, Henry VIII clauses.

Palabras Clave: Brexit, Unión Europea, Tratados internacionales (retirada), Artículo 50 TUE, Reino Unido, Asunto Miller, Prerrogativa regia, European Communities Act 1972, Escocia, Irlanda del Norte, cláusulas Enrique VIII.

FECHA DE RECEPCIÓN: 05.09.2017

FECHA DE ACEPTACIÓN: 21.09.2017

UNED. Teoría y Realidad Constitucional, núm. 40, 2017, pp. 111-140 